\title{
A Study on Radiofrequency volumetric tissue reduction of hypertrophied inferior turbinate in chronic nasal obstruction patients
}

\author{
Authors \\ Ashok Sharma, Pulkit Khandelwal, Meenakshi Mehra, Madhurima Baneerjee, \\ Vivek Taneja
}

\begin{abstract}
To assess the treatment of hypertrophy of inferior turbinates in patients with chronic nasal obstruction with the use of radiofrequency volumetric tissue reduction technique. Ablation with radiofrequency was used in this study on the inferior turbinates of 240 patients with chronic nasal obstruction at our hospital between December 2015 and December 2017. The results were evaluated subjectively by changes in pre and postoperative symptoms, size of inferior turbinate, postoperative pain and assessment of Eustachian tube function by looking at retraction of tympanic membrane. In our study nasal obstruction, nasal discharge, sneezing, snoring, hyposmia improved in 86\%, 93\%, 90.2\%, 33\%, 60\% respectively at the end of 1 month and symptoms further improved to $95 \%, 100 \%, 90 \%, 91 \%, 100 \%$ at the end of 1 year. Similarly $35 \%$ patients showed reduction in turbinate in first 7 days and $80 \%$ of the reduction of inferior turbinate took place at the end of 1 month. Further improvement was seen at the end of 3 month, approximately $95 \%$ patients showed reduction of inferior turbinate. And no significant difference was seen between 6 month and 12 months. Post-operatively $80 \%$ of patients with grade 1 and grade 2 tympanic membrane retractions showed improvement. On the contrary no improvement was seen in patients with grade 3 and 4 retractions.

These results suggests that radiofrequency volumetric tissue reduction of inferior turbinate is an easily applied, efficient and reliable technique in the treatment of hypertrophied inferior turbinate in chronic nasal obstruction patients.
\end{abstract}

Keywords: Radiofrequency ablation, inferior turbinate, tympanic membrane retraction, nasal obstrcution.

\section{Introduction}

One of the most common human problems encountered in the ear, nose, and throat specialty is Chronic nasal obstruction. The most common cause of this being hypertrophy of inferior turbinate. This may be related to allergy, pseudoallergy, nonallergic rhinitis with eosinophilia syndrome, and iatrogenic rhinopathy ${ }^{[1,2]}$. Numerous interventions are available which include medical treatments (topical decongestants, antihistamines, intranasal corticosteroid, immunotherapy) and surgical options (corticosteroid turbinate injections, cryosurgery, electrocautery, turbinate out-fracture, microdebrider-assisted turbinoplasty, excision and submucous resection) ${ }^{[3,4]}$. Even though medical treatments are frequently effective to restore comfortable nasal breathing, nasal obstruction is sometimes slightly improved, making some patients to increase their consumption of local decongestants with a high risk of iatrogenic effects. In these cases, surgical reduction of 
inferior turbinates can be proposed. The goals of inferior turbinate surgery include volume reduction, a reduction in nasal obstruction, and maintenance of nasal function while minimizing complications $^{[5-8]}$. But adverse events in surgery do occur, which include postoperative bleeding, crusting, foul odour, pain, hyposmia and synechiae $e^{[9,10]}$. There is currently no consensus on the most optimal technique. Nowdays, temperature-controlled radiofrequency tissue volume reduction (TCRFTVR) has been used for the treatment of the hypertrophied inferior turbinates. Radiofrequency tissue reduction is a surgical technique that uses radiofrequency heating to induce sub mucosal tissue destruction, leading to the reduction of tissue volume ${ }^{[11]}$. This energy induces ion agitation within the tissue, which increases the local temperature and causes a thermal lesion that should occur in the deep mucosa without damaging the surface. The healing process secondarily induces fibrosis with wound contraction, leading to tissue volume reduction $^{[12]}$. Radiofrequency ablation is an efficient, easily applicable technique, which does not lead to serious complications in the treatment of the nasal obstruction caused by inferior turbinate hypertrophy ${ }^{[13]}$.

\section{Study Design}

It is a non randomized prospective study on patients diagnosed with chronic nasal obstruction who underwent radiofrequency reduction of inferior turbinates between December 2015 till December 2017 at Sanjay Gandhi Memorial Hospital, Mangolpuri, New Delhi. 240 patients were enrolled in the study. All the patients had nasal blockage despite medical treatment. The study was aimed at recording the effects of radiofrequency reduction of the inferior turbinate on the nasal symptomatology and physiological function of the nose with Eustachian tube function by observing patients grade of tympanic membrane retraction according to sade's classification. All patients provided written informed consent before being included in the study, which was approved by the ethics committee.

\section{Inclusion Criteria}

(1) Patients aged between 15 and 60 years,

(2) Patients with symptoms of rhinitis with h/o incomplete/failed treatment by medical methods (topical decongestant, nasal steroids sprays, oral antihistamines)for more than 2 months.

\section{Exclusion Criteria}

(1) Previous nasal surgery,

(2) Recurrent epistaxis,

(3) Nasal polyps,

(4) Active respiratory tract infection,

(5) Patients with systemic diseases like diabetes mellitus, coagulation disorders, cardiac pacemaker and uncontrolled hypertension.

Preoperative complaints of patient included nasal obstruction, nasal discharge, sneezing, snoring, hyposmia. All patients were subjected to detailed history taking, General examination, Systemic examination, ENT examination, Diagnostic nasal endoscopic examination.

Inferior turbinate was graded into $1,2,3$ on the basis of size of the inferior turbinates.

No oedema: normal inferior turbinate.

Grade 1: Inferior turbinate is $25 \%$ of nasal cavity. Grade 2: Inferior turbinate is $50 \%$ of nasal cavity Grade 3: Inferior turbinate is $75 \%$ or more of nasal cavity.

Tympanic membrane retraction was graded according to Sade's classification

Grade 1: Slight retraction of TM over annulus

Grade 2: Severe retraction- TM touches long process of incus

Grade 3: Atelectasis- TM touches the promontory Grade 4: Adhesive otitis- TM adherent to the promontory

Follow up of patients were done after 3 days, 7days, 1 months, 3 month, 6 month and 12 months for improvement of symptoms. 


\section{Procedure}

The inferior turbinates are composed of osseous and mucosal parts. Although inferior turbinate hypertrophy is generally due to mucosal hypertrophy, osseous hypertrophy is also encountered in some patients. Topical vasoconstrictive agent application on the inferior turbinate prior to intervention allowed differentiation between pure osseous hypertrophy and mucosal hypertrophy. As RFA would be of no benefit in patients with pure osseous part hypertrophy, this distinction was significant. Radiofrequency reduction of the inferior turbinate was done under local anesthesia. Patient was placed in supine position with 15 degree head elevation. Patient nose was packed with $4 \%$ xylocaine $15 \mathrm{~min}$ before shifting into the theatre. Both the inferior turbinates were infiltrated with $2 \% x y l o c a i n e$ with 1 in 100000 adrenaline. Radiofrequency energy is applied submucosally along the length of the inferior turbinate for 3-4 s and the application is repeated. Same procedure was repeated on the other side with the radiofrequency probe. The advantage of this method was that postoperative nasal packing was not required in any of the cases. All the cases were discharged on the same day of surgery. Post operatively patients were advised antibiotics, antihistamines, and $\mathrm{NaCl}$ and sodiumbicarbonate nasal douching.

Patients were asked to come for post operative follow up after 3days, 1 week, 1 month, 3 month, 6 month and 12 months. Patient's symptomatology (nasal obstruction, nasal discharge, headache, sneezing, hyposmia) were recorded and compared with preoperative symptoms. Post operatively patients complained of nasal block and discharge for 3 days due to radiofrequency application over the inferior turbinates. Post operatively size of the inferior turbinate and retraction of tympanic membrane was compared with the preoperative findings. All the symptoms and signs were recorded. Postoperative pain assessment was done by visual analog scale.

\section{Results}

\section{Pre Operative Symptoms}

Of the 240 patients 132 were male and 108 were female and their ages ranged from 15 to 60 years. Pre operatively all 240 patients presented with nasal obstruction, associated symptoms of nasal discharge in 96 out of 240 patients (40\%), sneezing in 144 patients $(60 \%)$, snoring in 60 patients $(25 \%)$ and hyposmia in 5 patients $(2 \%)$ (Fig. 1).

Figure 1 pre operative symptoms

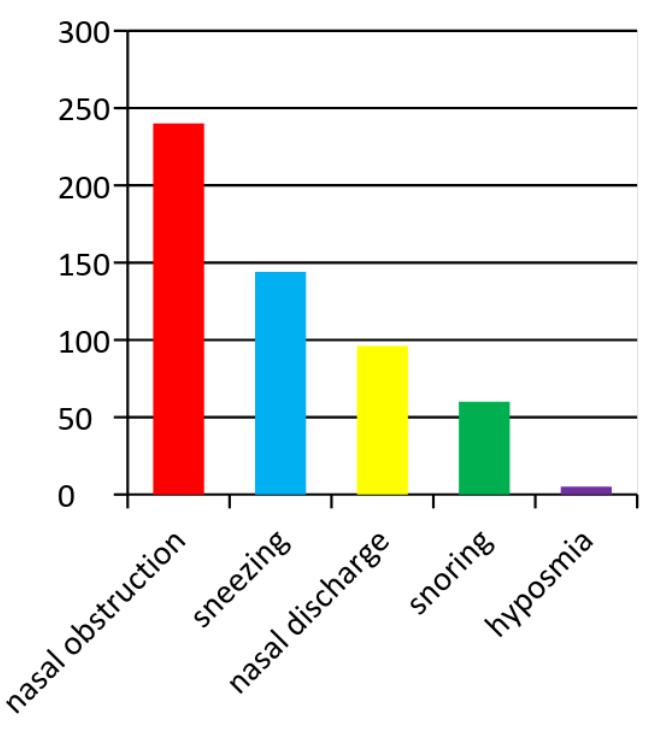

\section{Post Operative Symptoms (fig2 and table1)}

From the endoscopy performed in the days following the operation, we observed limited crusting on the surface of the turbinates where the needles were inserted and an edema with a more or less congested turbinate. All the patients complained of crusting in the first 3 days postoperative period which gradually reduced to 180 patients at 1 weeks, 10 patients at 1 month and no patients after 3 months [Fig. 3]. The patient's follow up enabled us to see that the mucosal surface normalized within 3-4 weeks. All the patients reported an improvement in their nasal obstruction in the checkups carried out after 1 weeks. 1 patient complained of bleeding in the first 3 days of post operative period. No patient complained of bleeding after that in post op period [Fig. 3]. There was no case of extended necrosis/atrophy of the inferior turbinate with the 
formation of persistent crusts and no sensation of nasal dryness and no post-operative synechiae.

Figure 2 post operative symptoms

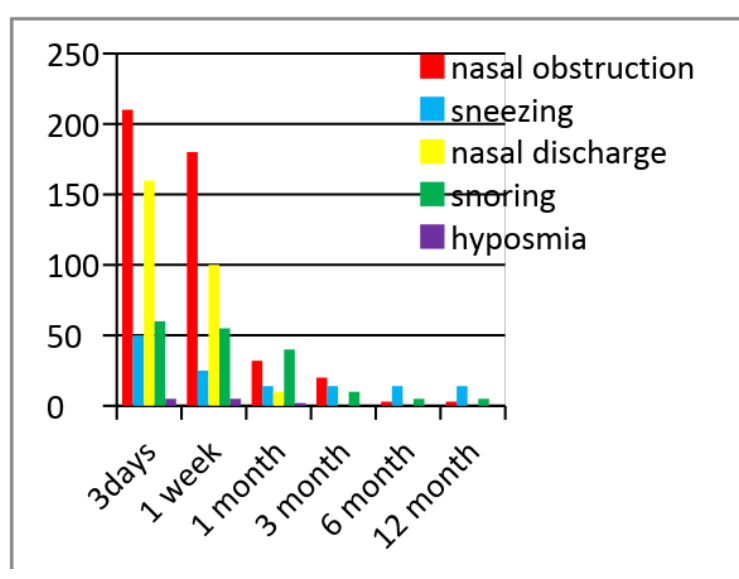

Table 1 : Post operative symptoms

\begin{tabular}{|l|c|c|c|c|c|c|}
\hline $\begin{array}{l}\text { Post- } \\
\text { operative } \\
\text { symptoms }\end{array}$ & 3 day & $\begin{array}{c}1 \\
\text { week }\end{array}$ & $\begin{array}{c}1^{\text {st }} \\
\text { month }\end{array}$ & $\begin{array}{c}3^{\text {rd }} \\
\text { month }\end{array}$ & $\begin{array}{c}6^{\text {th }} \\
\text { month }\end{array}$ & $\begin{array}{c}12^{\text {th }} \\
\text { month }\end{array}$ \\
\hline $\begin{array}{l}\text { Nasal } \\
\text { obstruction }\end{array}$ & 210 & 180 & 32 & 20 & 03 & 03 \\
\hline Sneezing & 50 & 25 & 14 & 14 & 14 & 14 \\
\hline $\begin{array}{l}\text { Nasal } \\
\text { discharge }\end{array}$ & 160 & 100 & 10 & 0 & 0 & 0 \\
\hline Snoring & 60 & 55 & 40 & 10 & 05 & 05 \\
\hline Hyposmia & 05 & 05 & 02 & 0 & 0 & 0 \\
\hline
\end{tabular}

Figure 3 Post operative complications

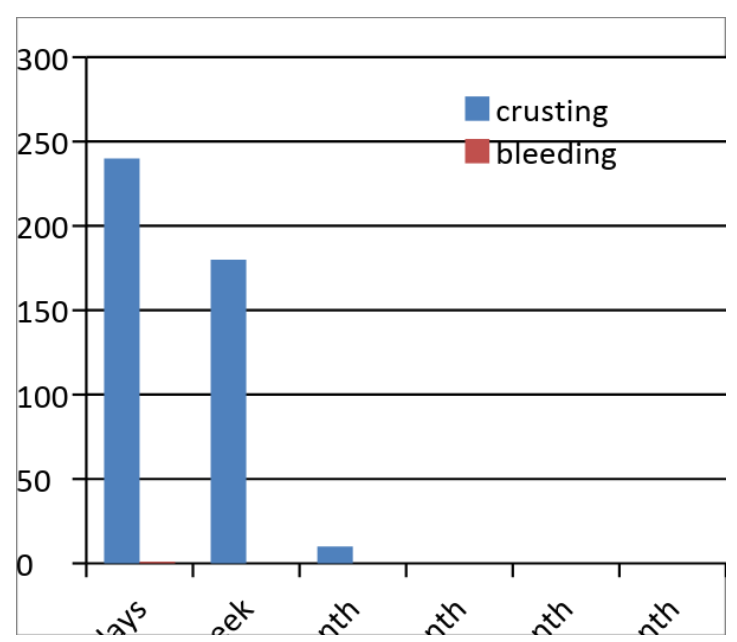

Post-Operative Size of Inferior Turbinate (Fig 4 and table 2)

Figure 4 Grading of inferior turbinate hypertrophy

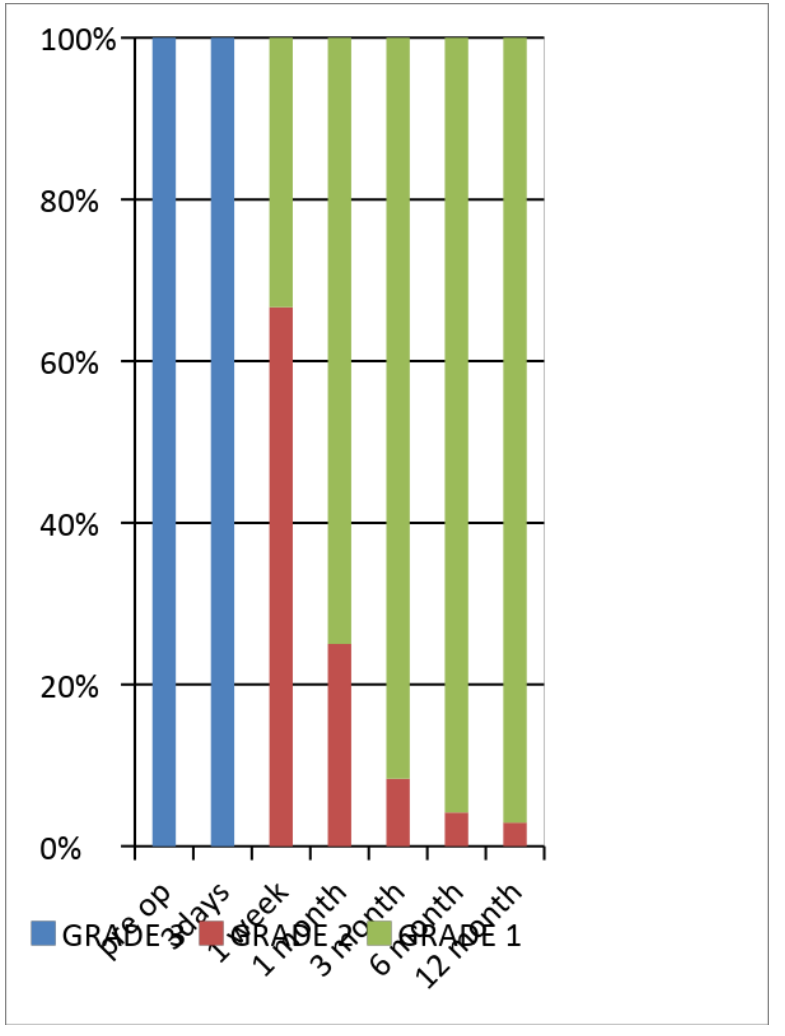

Table 2: Grading of inferior turbinate hypertrophy

\begin{tabular}{|l|c|c|c|}
\hline Grade & Grade 3 & Grade 2 & Grade 1 \\
\hline $\begin{array}{l}\text { Inferior turbinate } \\
\text { size pre-op }\end{array}$ & 240 & - & - \\
\hline IT 3 days post op & 240 & - & - \\
\hline IT 7 days post op & - & 160 & 80 \\
\hline IT 1 month post op & - & 60 & 180 \\
\hline IT 3month post op & - & 20 & 220 \\
\hline IT 6 month post op & - & 10 & 230 \\
\hline $\begin{array}{l}\text { IT 12 month post } \\
\text { op }\end{array}$ & - & 07 & 233 \\
\hline
\end{tabular}

\section{Assessment of Pain}

Post-operative pain was assessed using the visual analog scale for pain at 3 days, 1 week and 1 month post operatively. Patients were given questionnaires to scale the post operative pain on a scale of $0-10$. Of the 240 patients only 12 patients $(5 \%)$ complained of severe pain, 48 patients $(20 \%)$ mild pain, 180 patients $(75 \%)$ mentioned no pain post operatively 1 week following the procedure. No case of synechiae was observed in the follow up periods. 


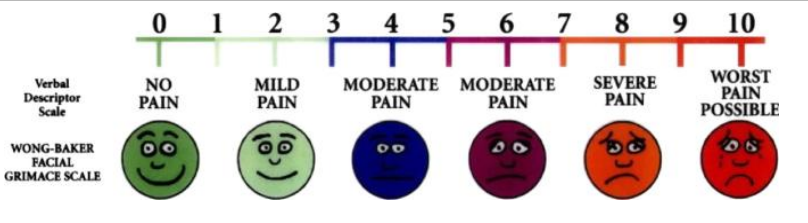

\section{Assessment of Eustachian tube (ET) Function}

Pre-operative Eustachian tube function was assessed by examining the ear of the patients. Out 240 patients $90(37.5 \%)$ patients did not had any retraction 150 patients had TM retractions, $70(29.1 \%)$ patients had grade 1, 50(20.8\%) patients grade $2,25(10.4 \%)$ had grade 3 and $5(2 \%)$ patients had grade 4.

Post-operative reassessment of patients was done. $80 \%$ of patients with grade 1 and grade 2 retractions showed improvement. On the contrary no improvement was seen in patients with grade 3 and 4 retractions.

\section{Discussion}

The accurate treatment of inferior turbinates hypertrophy has still not being found. Smith et al. showed that $90 \%$ of the reduction in the turbinate occurred in the first 21 days, that $100 \%$ of the reduction took place at the end of week 8 , and that there was no statistically significant difference between the evaluation at the end of week 8 and at the end of 1 year ${ }^{[14]}$. In our study approximately $35 \%$ patients showed reduction in turbinate in first 7 days and $80 \%$ of the reduction of inferior turbinate took place at the end of 1 month. Further improvement was seen at the end of 3 month, approximately $95 \%$ patients showed reduction of inferior turbinate. And no significant difference was seen between 6 month and 12 months. Parida et al in their study found that symptomatic improvement in nasal obstruction, rhinorrhea, sneezing, headache, hyposmia and snoring seen in $89.4 \%, 95.6 \%, 97.8 \%, 88.5 \%, 46.7 \%$ and $100 \%$ of patients respectively during 6 months followup $^{[15]}$. In our study nasal obstruction, nasal discharge, sneezing, snoring, hyposmia improved in $86 \%, 93 \%, 90.2 \%, 33 \%, 60 \%$ respectively at the end of 1 month and symptoms further improved to $95 \%, 100 \%, 90 \%, 91 \%, 100 \%$ at the end of 1 year. Radiofrequency reduction of hypertrophied inferior turbinate has a advantage that it is safe and convenient procedure. It is a day care procedure with very few complications. It is cost effective as compared to other treatment modalities, but equally effective as compared to other treatment modalities.

\section{Conclusion}

Radiofrequency volumetric tissue reduction of hypertrophied inferior turbinate is a cost effective day care procedure with very rare minor complication with a promising future.

\section{References}

1. Lippert BM, Werner JA (1996) Nd: YAG laser light-induced reduction of nasal turbinates. Laryngorhinootologie 75:523528

2. Ottaviani F, Capaccio P, Cesana BM et al (2003) Argon plasma coagulation in the treatment of nonallergic hypertrophic inferior nasal turbinates. Am J Otolaryngol 24:306-310

3. Elwany S, Gaimaee R, Fattah HA. Radiofrequency bipolar submucosal diathermy of the inferior turbinates. Am J Rhinol 1999;13:145-9.

4. Sapçi T, Sahin B, Karavus A, Akbulut UG. Comparison of the effects of radiofrequency tissue ablation, $\mathrm{CO} 2$ laser ablation, and partial turbinectomy applications on nasal mucociliary functions. Laryngoscope 2003;113:514-9.

5. Sapci T, Sahin B, Karavus A et al (2003) Comparison of the effects of radiofrequency tissue ablation, $\mathrm{CO} 2$ laser ablation, and partial turbinectomy applications on nasal mucociliary functions. Laryngoscope 103:514-519

6. Elwany S, Gaimaee R, Fattah HA (1999) Radiofrequency bipolar submucosal diathermy of the inferior turbinates. Am J Rhinol 13:145-149

7. Smith TL, Correa AJ, Kuo T et al (1999) Radiofrequency tissue ablation of the 
inferior turbinates using a thermocouple feedback electrode. Laryngoscope 109:1760-1775

8. Rhee CS, Kim DY, Won TB et al (2001) Changes of nasal function after temperature-controlled radiofrequency tissue volume reduction for the turbinate. Laryngoscope 111:153-158

9. Elwany S, Gaimaee $R$, Fattah HA. Radiofrequency bipolar submucosal diathermy of the inferior turbinates. Am J Rhinol 1999;13:145-9.

10. Utley DS, Goode RL, Hakim I. Radiofrequency energy tissue ablation for the treatment of nasal obstruction secondary to turbinate hypertrophy. Laryngoscope 1999;109:683-6.

11. Sapci T, Usta C, Evcimik MF, Bozkurt Z, Aygun E, Karavus A, et al. Evaluation of radiofrequency thermal ablation results in inferior turbinate hypertrophies by magnetic resonance imaging. Laryngoscope 2007;117:623-7.

12. Powell NB, Riley RW, Troell RJ, Li K, Blumen MB, Guilleminault C. Radiofrequency volumetric tissue reduction of the palate in subjects with sleep-disordered breathing. Chest 1998;113:1163-74.

13. Hytönen ML, Bäck LJ, Malmivaara AV, Roine RP. Radiofrequency thermal ablation for patients with nasal symptoms: a systematic review of effectiveness and complications. Eur Arch Otorhinolaryngol 2009;266:1257-66.

14. Smith TL, Correa AJ, Kuo T, Reinisch L (1999) Radiofrequency tissue ablation of the inferior turbinates using a thermocouple feedback electrode. Laryngoscope 109:1760-1765

15. Parida $\quad \mathrm{PK}^{1}$, Santhosh $\mathrm{K}$, Ganesan S, Surianarayanan G, Saxena SK. (2011) The efficacy of radiofrequency volumetric tissue reduction of hypertrophied inferior turbinate in allergic rhinitis. Indian J Med
Sci. 2011

Jul;65(7):269-77. 10.4103/0019-5359.107387. doi: 